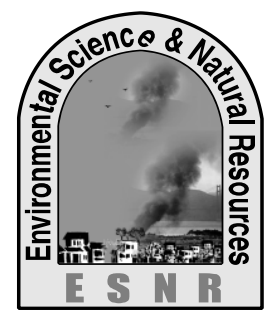

\title{
Diurnal Variation of Carbon Dioxide Flux Over Rice Paddy
}

\author{
M. A. Islam ${ }^{1}$, M. Mano ${ }^{2 *}$, M. S. Hossen ${ }^{1}$, A. Miyata ${ }^{3}$ and M. A. Baten ${ }^{1}$ \\ ${ }^{1}$ Department of Environmental Science, Bangladesh Agricultural University, Mymensingh-2202 \\ ${ }^{2}$ Graduate School of Horticulture, Chiba University, Matsudo-Shi, 271 Chiba, Japan \\ ${ }^{3}$ National Institute for Agro-Environmental Sciences, Tsukuba, Japan \\ *Corresponding author: mano@chiba-u.jp
}

\begin{abstract}
An experiment was conducted to measure carbon dioxide $\left(\mathrm{CO}_{2}\right)$ flux by using the eddy covariance technique over rice paddy field at Mymensingh flux study site at Bangladesh Agricultural University, Mymensingh at three growing stage in Aman season in 2015. The variation of $\mathrm{CO}_{2}$ flux in the experimental period displayed distinct diurnal variations as influenced by rice growth and development. The diurnal pattern of $\mathrm{CO}_{2}$ flux showed broad peak at flowering stage of Aman rice at DOY 285 due to photosynthesis. The diurnal pattern of $\mathrm{CO}_{2}$ flux showed also higher broad peak at 1500 hour in DOY 272 at vegetative stage and lower broad peak at 1300 hour in DOY 330 ripening stage of Aman rice due to photosynthesis, meteorological conditions and field management activities.
\end{abstract}

Key words: Aman rice, Flowering, Ripening and Vegetative stage

\section{Introduction}

The increase of the world economic activities currently results in the rising of carbon dioxide and other greenhouse gases from burning fossil fuel, automobile exhaust and industrial sources, which contributes significantly to global warming resulting climate change (IPCC, 2013). So, anthropogenic production of $\mathrm{CO}_{2}$ is the central concern among the scientists working in the field of global warming. Under growing concern on global warming, role of terrestrial ecosystem including croplands in the global carbon and GHG budget are now investigated worldwide under the leadership of AsiaFlux Research Group Japan, South Korea, Bangladesh, China and Philippine. According to IPCC report (AR4, 2007), despite large annual exchanges of $\mathrm{CO}_{2}$ between the atmosphere and agricultural lands, the net flux is estimated to be approximately balanced, but uncertainty level of this statement is low agreement and having limited evidences. Active $\mathrm{CO}_{2}$ exchange is occurring between the terrestrial ecosystem and the atmosphere through (I) photosynthesis and respiration of plants and (II) decomposition of soil organic matters. Despite its importance both in land coverage and in food production in the world, a small number of studies have been done on carbon exchanges between rice paddy fields and the atmosphere (Miyata et al., 2000; Campbell et al., 2001; Saito et al., 2005; Alberto et al., 2009; Alberto et al., 2012).

Micrometeorology is the new area of research in Bangladesh where micrometeorological investigation concerning crop growth and development are very rare. Baten and his group [https://mlshare.sys.affrc.go.jp/mym/mym_public/] were the leading scientists in Bangladesh to begin research on crop microclimate/crop micrometeorology using traditional instruments till early 2005 (Farukh et al., 2005; Farukh and Baten, 2005; Khatun et al., 2005; Khatun and Baten, 2005; Hossen et al., 2005). To evaluate $\mathrm{CO}_{2}$ exchanges over rice fields in Bangladesh, Scientists from NIAES, Tsukuba, Japan in Collaboration with Department of Environmental Science, BAU, Mymensingh started long-term flux measurement over typical double cropping rice paddy field (Rice-Fallow-Rice, i.e. Boro-Fallow-Aman) of BAU in February 2006 installing a tower setting sophisticated instruments for fluxes $\left(\mathrm{CO}_{2}\right.$ and Energy) and various meteorological parameters. This tower is known as Mymensingh Flux Tower. Keeping the above views in mind, the present piece of research work was undertaken with the following objectives:

1) to make clear the diurnal variation of $\mathrm{CO}_{2}$ flux among Aman seasons;

2) to report the causes of $\mathrm{CO}_{2}$ flux variation among the cropping seasons.

\section{Materials and Methods}

\section{Geographical location of the study site}

This study was conducted in the Mymensingh flux study site, called MYM site (three letter international code name for Asia Flux). It is located in the Agriculture Farm, Bangladesh Agricultural University $\left(24^{\circ} 43^{\prime} 31.0^{\prime \prime} \mathrm{N}\right.$ or $24.72528^{\circ} \mathrm{N}, 90^{\circ} 25^{\prime} 27.3^{\prime \prime} \mathrm{E}$ or $90.42425^{\circ} \mathrm{E}$; $18 \mathrm{~m}$ above sea level), $6 \mathrm{~km}$ to the south of Mymensingh town and $115 \mathrm{~km}$ to the north of Dhaka, the capital city of Bangladesh (Fig.1). This extensive field (about 78.28 ha) has been used only for paddy cultivation for 54 years from the beginning of University in 1961, and provides sufficient upwind fetch $(>300 \mathrm{~m}$ to the south, $>500 \mathrm{~m}$ to the west, and about $200 \mathrm{~m}$ to the north and east of the measuring tower) of uniform cover required for measuring mass and energy fluxes using tower-based eddy covariance systems.

\section{Cropping patterns}

The rice growing period was two seasons: Boro (January to May) and Aman (August to December) in a year. Common cropping patterns using there since long are irrigated Boro rice, a fallow period, and rain feed Aman rice. The field was mostly flooded except ripening stage by rain fed water (Aman season) or irrigated water (Boro season). After Boro season there was no crop cultivated in the study area for about 90 days (middle May to middle August). Weeds and various aquatic plants were found to grow during the 
fallow period. After Aman season, on the other hand, crop residue was taken out and the field had no plants.
In this study, we focused the diurnal $\mathrm{CO}_{2}$ flux pattern in Aman season.

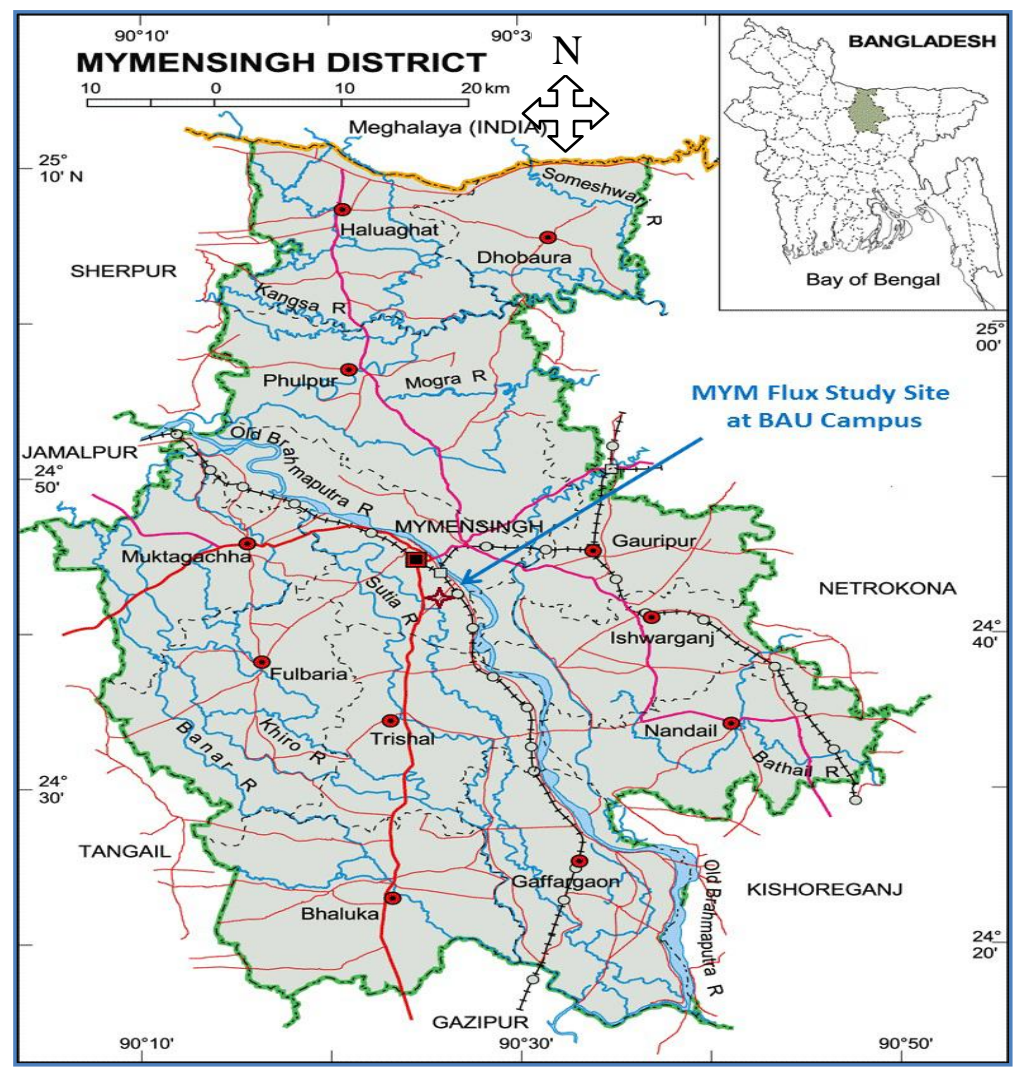

Fig. 1. Study area at Mymensingh district

Rice was grown under recommended cultural practices under the active supervision of Central Farm Authority of Bangladesh Agricultural University. Observation was made without any influence on the rice paddy ecosystem to measure the status of radiation and energy balance.

\section{Flux measurement systems}

\section{Eddy covariance (EC) measurement}

In our flux study site, flux densities of sensible heat and carbon dioxide and water vapor were measured by the eddy covariance method using a sonic anemometer (R3, Gill, UK) and an open-path infrared gas analyzer (LI7500, LICOR, USA). Three wind components and acoustic virtual temperature measured with the sonic anemometer, and densities of carbon dioxide and water vapor density measured with the infrared gas analyzer were sampled at $10 \mathrm{~Hz}$ interval (10 times per second), and recorded with a data logger (CR3000, Campbell Scientific, USA).

\section{Data collection and mathematical interpolation}

Data were collected weekly, and additional data processing (e.g. transfer files from the data logger, and file conversion from Binary to ASCII and) was done by our computers at Micrometeorology Laboratory, Department of Environmental Science, Bangladesh Agricultural University, Mymensingh.

\section{Maintenance}

Research team of the project (professors and scientists) checked the micro-meteorological instruments at an interval of 7 to 10 days. In case of serious problem, advice was taken from our collaborator scientists of NIAES, Tsukuba, Japan. NIAES team also visits 2 to 3 times in a year to check in details. Data were retrieved during instrument checking. In case of sensor problem of any kind, it was tried heart and soul to fix/repair without any delay. Leveling of radiation sensors (MR40, EKO, Japan) were checked regularly. Ventilators for temperature-humidity sensors (HMP45A, Vaisala, Finland) were checked once a year and dust accumulated in the ventilation tube was removed. We always put high attention to take care of all instruments.

\section{Data analysis}

Data analyses were performed using Microsoft Excel 2010 (Microsoft Corp.). Graphs were also prepared by the above mentioned software.

\section{Quality control of data}

Continuous measurement of meteorological data may introduce errors due to various causes, viz. malfunctioning of instruments, inappropriate atmospheric conditions, rainfall or human disturbance etc. So it is needed to control the quality of meteorological data. Graph of time series of half-hourly meteorological data were prepared and observed abnormalities such as discontinuities and unrealistic 
diurnal variations were flagged. After doing data quality, missing half-hourly values of incoming short-wave radiation, air temperature, relative humidity and barometric pressure were filled at NIAES Laboratory.

\section{Processing of eddy covariance data}

\section{Flux calculation}

Before calculating covariance between a wind velocity component and a scalar quantity, wind velocity components were rotated by applying planar fit method (Wilczak et al., 2001). In this study, the sectorial planar fit was used, in which the mean stream plane was determined at each wind sector of a center angle of $90^{\circ}$, was used. The sectorial planar fit is a practical alternative to the ordinary planar fit when the mean stream surface is not approximated by a plane (Ono et $a l .$, 2007). The annual dataset was split into four periods (two rice growing periods and two fallow periods), and the parameters for the sectorial planar fit were determined in each of the four periods. Frequency losses due to path-length averaging and the separation between the anemometer and the IRGA were corrected following a procedure proposed by Massman (2000), but crosswind correction to sensible heat flux was not applied because the crosswind effect was corrected automatically in internal processing of Gill sonic anemometer.

$\mathrm{CO}_{2}$ flux density, $F_{\mathrm{c}}$, is the amount of $\mathrm{CO}_{2}$ passing through a unit cross-section area per unit time,

$F_{\mathrm{c}}=\overline{w^{\prime} c^{\prime}}(1)$

where $w$ is vertical wind velocity $\left(\mathrm{m} \mathrm{s}^{-1}\right), c$ is molar density of $\mathrm{CO}_{2}\left(\mu \mathrm{mol} \mathrm{m} \mathrm{m}^{-3}\right)$, and the prime and overbar denote the perturbed and basic mean, respectively. The standardized corrections, including the so-called WPL correction (Webb et al., 1980), of $F_{\mathrm{c}}$ (Foken, 2008) were applied and quality.

\section{Results and Discussion}

Diurnal variation $\mathrm{CO}_{2}$ Flux $\left(\mathrm{F}_{\mathrm{c}}\right)$ over rice field on Aman Season 2015

The maximum and minimum value of $F c$ in the vegetative stage in Aman rice were -17.1 micro-molm ${ }^{2} \mathrm{~s}^{-1}$ at $1500 \mathrm{~h}$ and 4.7 micro-molm ${ }^{-2} \mathrm{~s}^{-1}$ at $1900 \mathrm{~h}$ due to photosynthesis and respiration (Fig. 2). Positive value indicate the $\mathrm{CO}_{2}$ emits from the ecosystem due to respiration and negative value indicate the $\mathrm{CO}_{2}$ absorbs from the atmosphere for photosynthesis.

The maximum and minimum value of $F_{\mathrm{c}}$ in the flowering stage in Aman rice were -24.1 micro-molm ${ }^{-2} \mathrm{~s}^{-}$ ${ }^{1}$ at $1100 \mathrm{~h}$ and 3.1 micro-molm $\mathrm{s}^{-2}$ at $0300 \mathrm{~h}$ due to photosynthesis and cloudy condition (Fig. 3). The diurnal pattern of $\mathrm{CO}_{2}$ flux $\left(F_{\mathrm{c}}\right)$ showed broad peak at flowering stage of Aman rice at DOY 285 due to photosynthesis. With growing the rice, higher photosynthesis of larger leaves resulted in the higher $\mathrm{CO}_{2}$ uptake compared with the vegetative stage.
The maximum and minimum value of $F_{\mathrm{c}}$ in the ripening stage just before harvest of Aman rice were -8.0 micromolm $\mathrm{s}^{-1}$ at $1300 \mathrm{~h}$ and 5.4 micro-molm $\mathrm{s}^{-2}$ at $0300 \mathrm{~h}$ due to low photosynthesis activity during senescence

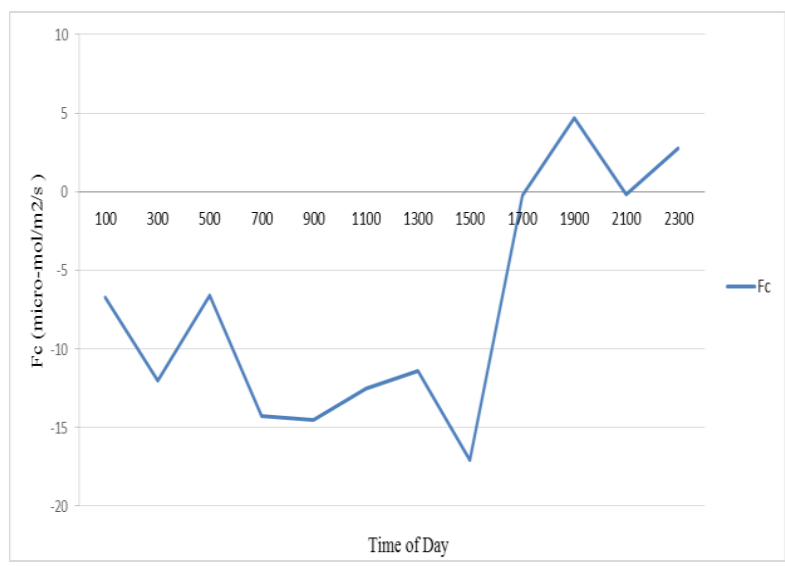

Fig. 2. Diurnal pattern of $\mathrm{CO}_{2}$ flux $\left(F_{\mathrm{c}}\right)$ at vegetative stage of Aman rice field (DOY 272) with the time of day (h).

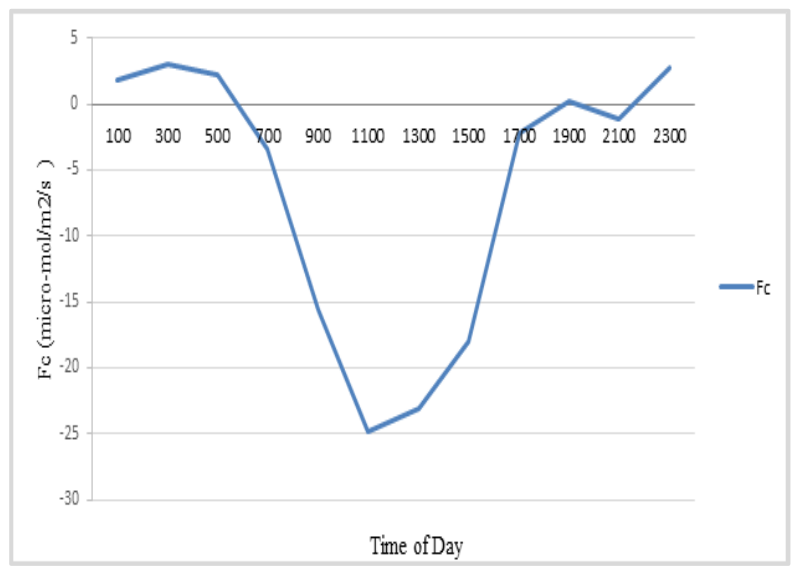

Fig. 3. Diurnal pattern of $F_{\mathrm{c}}$ at flowering stage of Aman rice field (DOY 285) with the time of day (h).

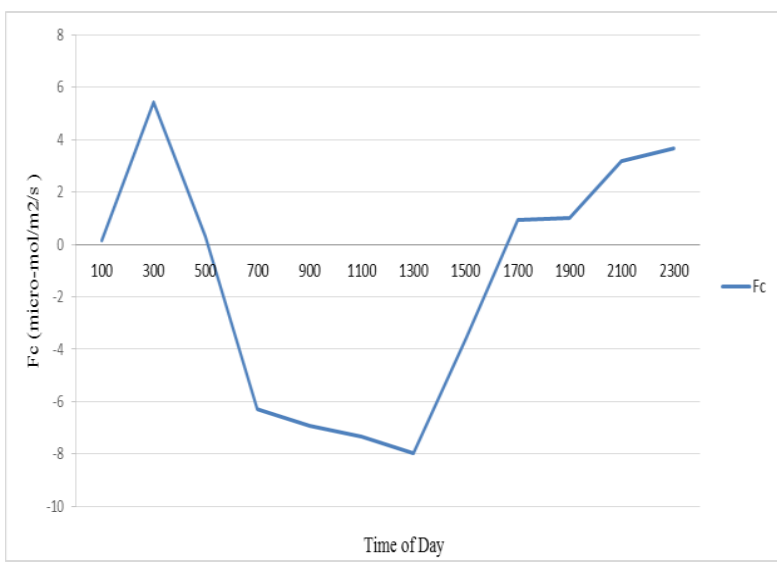

Fig. 4. Diurnal pattern of $\left(F_{\mathrm{c}}\right)$ ripening stage of Aman rice field (DOY 330) with the time of day (h). and cloudy weather condition (Fig. 4). Because the rice biomass was increased at this stage, higher $\mathrm{CO}_{2}$ efflux due to its respiration was observed during nighttime. 


\section{Conclusions}

Agricultural areas comprise a large portion of the land surface of the earth. Under the current climate and environmental changes, the role of cropland ecosystems in the surface-atmosphere $\mathrm{CO}_{2}$ flux, energy and matter exchange has drawn a lot of attention. We have investigated the potential change on rice ecosystematmosphere exchange of heat, vapor pressure deficit and carbon dioxide in the past years. The eddy-covariance technique was used to observe carbon dioxide exchange, and energy fluxes of sensible and latent heat with additional measurements of meteorological variables and biomass change. This research was conducted to measured carbon dioxide $\left(\mathrm{CO}_{2}\right)$ flux and its diurnal variation at customarily cultivated paddy field in northern Bangladesh at Mymensingh flux study site at Bangladesh Agricultural University, Mymensingh during the Aman season in 2015. In this study, the diurnal variation of $\mathrm{CO}_{2}$ flux $\left(F_{\mathrm{c}}\right)$ at vegetative, flowering and ripening stages was observed and, the different peaks with the time variation due to photosynthesis, respiration, meteorological conditions were discerned. The results of present study recommend that needed quantitative discussion including other carbon budget components which help us to controlling carbon budget of the paddy field, assessment on crop production and improvement the management of field activities which help us to meet the reduction of GHG gases.

\section{References}

Alberto, M. C. R.; Hirano, T.; Miyata, A.; Wassmann, R.; Kumar, A.; Padre, A. and Amante, M. 2012. Influence of climate variability on seasonal and interannual variations of ecosystem $\mathrm{CO}_{2}$ exchange in flooded and non -flooded fields in the Philippines. Fiel. Cro. Res., 134: 80-94.

Alberto, M. C. R.; Wassmann, R.; Hirano, T.; Miyata, A.; Kumar, A.; Padre, A. and Amante, M. 2009. $\mathrm{CO}_{2}$ /heat fluxes in rice fields: Comparative assessment of flooded and non -flooded fieldsin the Philippines. Agric. For. Meteorol., 149: 1737-1750.

AR4 (Fourth Assessment Report). 2007. Climate Change 2007: The Physical Science Basis, Contribution of Working Group I to the Fourth Assessment Report of the Intergovernmental Panel on Climate Change, Solomon, S.; Qin, D.; Manning, M.; Chen, Z.; Marquis, M.; Averyt, K. B.; Tignor, M.; Miller, H. L. (Eds), IPCC, Cambridge University Press, Cambridge, 996p.

Cambell, C. S.; Heilman, J. L.; McInnes, K. J.; Wilson, L. T.; Medley, J. C.; Wu, G. and Cobos, D. R.
2001.Diurnal and seasonal variation in $\mathrm{CO}_{2}$ flux of irrigated rice. Agric. For. Meteorol., 108:15-27.

Farukh, M. A. and Baten, M. A. 2005. Investigation of a Few Micrometeorological Parameters over Fallow Land Vegetation. J. Bangladesh Soc. Agric. Sci. Technol., 2(1\&2): 1-5.

Farukh, M. A.; Sattar, M. A. and Baten, M. A. 2005. Investigation of Energy Balance Components over Vegetation of Fallow Land. Bangladesh J. Environ. Sci., 11(1):114-118.

Foken, T. 2008. Micrometeorology. Springer-Verlag, Berlin, Heidelberg.

Hossen, M. S.; Nahar, F.; Khatun, R.; Nahar, B. S.; Miyata, A.; and Baten, M. A. 2005. Effect of Rice Growth on Absorptivity, Reflectivity and Transmissivity of Light. Bangladesh J. Environ. Sci. 11(2): 242-245.

IPCC (Intergovernmental Panel on Climate Change). 2013. The Physical Science Basis. Working Group I Contribution to the Fifth Assessment Report of the Intergovernmental Panel onClimate Change. Cambridge University Press, Cambridge, 1535 p.

Khatun, R. and Baten, M. A. 2005. Effect of Different Row Orientations of Maize on Energy Balance Components and Canopy Heat Storage. Bangladesh J. Environ. Sci., 11(2): 238-241.

Khatun, R.; Miyata, A. and Baten, M. A. 2005. Micrometeorological Parameters over Irrigated Rice Field. J. Bangladesh Soc. Agric. Sci. Technol., 2(3\&4): 61-64.

Massman, W. 2000. A simple method for estimating frequency response corrections for eddy covariance systems. Agric. For. Meteorol., 104: 185-198.

Miyata, A.; Leuning, R..; Denmead, O.; Kim, J. and Harazono, Y. 2000. Carbon dioxide and methane fluxes from an intermittently flooded paddy field. Agric. For. Meteorol., 102: 287- 303.

Ono, K.; Mano, M.; Miyata, A. and Inoue, Y. 2007. Applicability of the planar fit techniquein estimating surface fluxes over flat terrain using eddy covariance. J. Agric.Meteorol., 64(3): 121-130.

Saito, M.; Miyata, A.; Nagai, H. and Yamada, T. 2005. Seasonal variation of carbon dioxide exchange in rice paddy field in Japan. Agric. For.Meteorol., 135(1-4): 93-109.Webb, E.K., G.I. Pearman, and R. Leuning. 1980. Correction of flux measurements for density effects due to heat and water vapour transfer. Q. J. R. Meteorol. Soc. 106:85-100.

Wilczak, J. M.; Oncley, S. P. and Stage, S. A. 2001. Sonic anemometers tilt correction algorithms. Boun. Lay. Meteorol., 99: 127-150. 